\title{
Assessment of the Daily Safety and Operations Huddle of a Pharmacy Department
}

\author{
Kenneth M Komorny ${ }^{1, *}$, Amy Rosenberg ${ }^{1}$, Emily McCleary ${ }^{2}$ \\ ${ }^{1}$ Department of Pharmacy, UF Health Shands, Gainesville, 32610, Florida, United States \\ ${ }^{2}$ University of Kentucky Chandler Hospital, Lexington Kentucky, 40536, United States
}

Copyright $@ 2018$ by authors, all rights reserved. Authors agree that this article remains permanently open access under the terms of the Creative Commons Attribution License 4.0 International License

\begin{abstract}
A daily huddle was tested in an academic medical center pharmacy department to see if it resulted in a positive impact on the safety culture and communication. The huddle is a short daily briefing conducted at shift change in a main pharmacy area with a dial in number for those not present in the main pharmacy area. The purpose of the huddle is to raise awareness of any current safety or operational issues. The effectiveness of the huddle was primarily tested through a targeted survey and the Agency for Healthcare Research and Quality (AHRQ) Patient Safety Culture Survey results. A survey evaluating daily huddle effectiveness had a $24 \%$ response rate. The majority of respondents indicated positive feelings towards the huddle: $58.7 \%$ indicated effective communication of information between shifts, $67 \%$ indicated effective communication of safety events, and $63 \%$ indicated effective communication of daily operational issues. Additionally, the department's AHRQ Patient Safety Culture Survey results improved following the huddle implementation. Departmental staff gave their work unit an overall safety score of the top possible answer, excellent, (vs. very good, acceptable, poor, failing) $11 \%$ of the time before the huddle began. Eight months after the huddle started, the number of respondents answering with the top possible score increased to $23 \%(\mathrm{p}<0.05)$. This positive impact sustained to the next year as well (25\% top possible score). Additional positive results are discussed. Implementation of a safety huddle positively influenced measures of communication and safety culture in the Department of Pharmacy Services.
\end{abstract}

Keywords Daily Briefing, Huddle, Safety Culture

\section{Introduction}

Daily safety briefings or huddles have been used in patient care settings as a tool to enhance open team communication around patient safety and operational efficiency. The Institute for Healthcare Improvement, The Joint Commission, and the Agency for Healthcare Improvement have recommended daily safety huddles as a tool that can be used to promote high reliability in a healthcare setting. [1-3] A safety huddle is a short, usually daily, briefing to share issues that occurred in the last 24 hours. Experience with huddles has been described in various healthcare settings. Examples include: nursing teams in critical care units, physician teams in brain and spinal cord injury rehabilitation hospitals, and information technology professional contribution to a hospital wide safety huddle. [4-6] Additionally pharmacist participation in hospital-wide huddles and patient care unit huddles has been described. $[7,8]$

In our hospital, safety huddles are routinely used on patient care units to achieve high reliability, and in recent years, our organization has initiated a larger hospital-wide huddle each morning. This huddle includes representatives from all patient care units and clinical operations departments.

Pharmacy departments, like direct patient care units, face daily operational challenges, need for work flow shifts, good team communication and transparency regarding safety events. Larger departments of pharmacy face additional communication barriers due to the need to geographically spread services and people across larger hospital settings. This study assesses pharmacy staff perceptions regarding the effectiveness of a huddle at enhancing communication and engagement surrounding operations and medication safety in an academic medical center department of pharmacy.

\section{Materials and Methods}

UF Health Shands is a large academic medical center that comprises 3 hospitals and is licensed for 1,111 beds. The hospital system provides comprehensive patient care, from primary care and family medicine to subspecialty 
tertiary and quaternary services for patients with highly complex medical conditions. The pharmacy department at UF Health Shands Hospital includes inpatient and outpatient services. The department utilizes a centralized/ decentralized pharmacy services model. Upon initiation of the safety huddle in August 2014, the department consisted of 9 main areas providing services throughout two hospital towers. This included two sterile compounding centers, two centralized medication carousel areas, a non-sterile compounding area, pharmacy stores, 8 satellite pharmacies, multiple clinical specialist pharmacists, and unit based pharmacists. The safety huddle was initiated Monday through Friday (a weekend safety huddle was also piloted). The safety huddle was held daily at 7:05 am. This time was chosen to allow the most overlap between day and night shift team members. The huddle duration was ideally intended to last from 3 to 7 minutes to allow for real time information sharing, while minimizing work flow impact. The huddle was held daily in the main central pharmacy area and a conference line was established to allow department members to call in. All department members were encouraged to participate in the daily huddle.

The huddle was led most days by the assistant director of pharmacy, but at least one day per week clinical staff pharmacists lead the huddle. Content for the huddle was provided the afternoon before by the medication safety pharmacist, pharmacy leadership team, and other members of the department who at times provided quick learning pearls related to de-identified patient cases. The topics covered in the huddle were structured to include: medication safety events, staffing issues, 6am bed occupancy, equipment issues, and open call for any issues experienced overnight or by anyone attending the huddle. The medication safety pharmacist provided de-identified information on medication safety events that happened the day before to facilitate transparency related to safety events. Following completion of the huddle, written notes from the discussion were posted to the Pharmacy portal on the hospital's website in case they were unable to dial in or attend the live huddle (Figure 1)

The huddle was also used, in 2014 to help drive completion of sterile product hood cleaning logs, a challenge the department was experiencing at the time. For a one-month period, during the huddle, all pharmacy areas with a sterile compounding hood were asked in a "roll call" fashion to indicate whether or not their hood cleaning logs were completed for the prior 24 hours. Failures were identified real time and responsible staff members were coached about the importance of documenting hood cleaning.

The impact of the safety huddle was measured using three tools: an anonymous survey with questions specific to huddle effectiveness sent to department members after 6 months of daily safety huddles, changes in the Agency for Healthcare Research and Quality (AHRQ) Patient Safety Culture survey results before and after initiation of the safety huddle, and completion of hood cleaning logs before and after implementation of the safety huddle. Because all survey information was anonymous and no employee or patient level identifying information was collected, the project was deemed to have "exempt" status by the institution's Institutional Review Board (IRB).

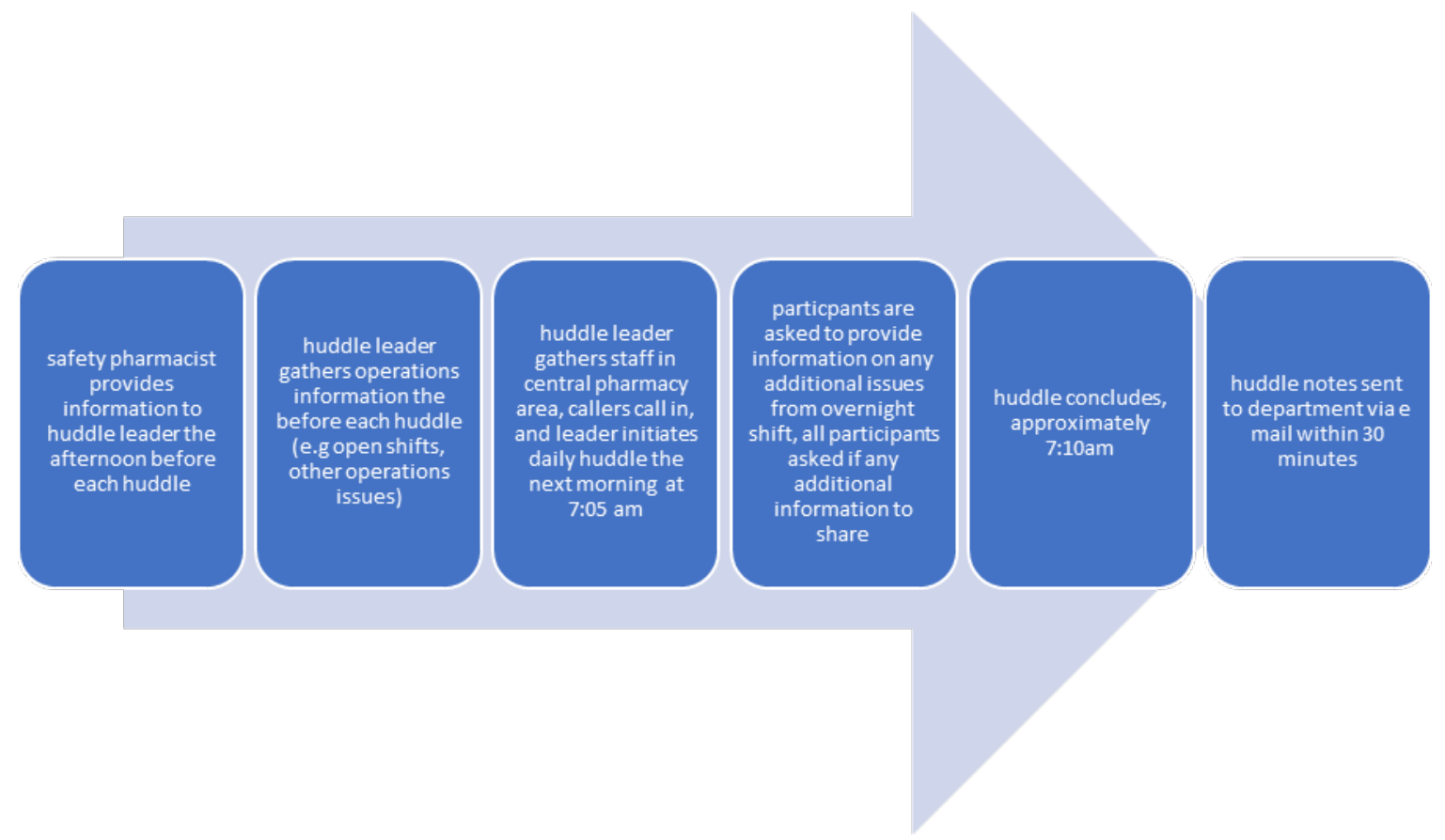

Figure 1. Safety and Operations Huddle Process 
The anonymous survey with questions specifically about the daily huddle was sent to department members via an email link using the institution's Redcap system. The survey included 10 questions (Table 1). In addition to conducting an anonymous survey focused specifically on the safety huddle, the department's results from the AHRQ Patient Safety Culture Survey were used as an indirect measure of possible impact a huddle had on the overall safety culture. The department had begun fully participating in the hospital-wide annual AHRQ Patient Safety Culture Survey in March of 2014, prior to implementation of the safety huddle. The department's overall safety score was compared prior to implementation of the daily huddle to the score the following year (2015). At this point the huddle had been implemented for 8 months. For each group the overall employee rated safety grade of "excellent" (vs. very good, acceptable, poor, failing) in the AHRQ Patent Safety Culture survey was compared using a two proportion hypothesis test with a finite population correction factor. Statistical significance was defined as a $\mathrm{p} \leq 0.05$. Lastly, sterile product hood cleaning log completion results were compared amongst the period prior to implementing daily roll calls for hood cleaning logs (9/01/ - 9/27/2014) and after adding this for a time to the daily huddle (10/6 11/1/2014). Chi square analysis was used to compare hood cleaning documentation before and after daily roll calls on the huddle with a $\mathrm{p} \leq 0.05$ to define statistical significance.

Table 1. Survey questions and responses

\begin{tabular}{|c|c|c|}
\hline & Survey question & Responses \\
\hline 1 & $\begin{array}{l}\text { The daily safety/operations huddle is designed to improve patient safety by sharing } \\
\text { useful information between shifts and alerting the Pharmacy Department to potential } \\
\text { safety issues. Please rate how effective you feel the huddle is at accomplishing this } \\
\text { goal }\end{array}$ & $\begin{array}{c}\text { Very ineffective } \\
\text { Somewhat ineffective } \\
\text { Neutral } \\
\text { Somewhat effective } \\
\text { Very effective } \\
\end{array}$ \\
\hline 2 & $\begin{array}{l}\text { Rate how you feel about this statement: The safety/operations huddle informs me } \\
\text { about safety issues }\end{array}$ & $\begin{array}{c}\text { Strongly disagree } \\
\text { Somewhat disagree } \\
\text { Neutral } \\
\text { Somewhat agree } \\
\text { Strongly agree }\end{array}$ \\
\hline 3 & $\begin{array}{l}\text { Rate how you feel about this statement: The safety/operations huddle informs me } \\
\text { about Pharmacy operations issues }\end{array}$ & $\begin{array}{c}\text { Strongly disagree } \\
\text { Somewhat disagree } \\
\text { Neutral } \\
\text { Somewhat agree } \\
\text { Strongly agree }\end{array}$ \\
\hline 4 & $\begin{array}{l}\text { Rate how you feel about this statement: The safety/operations huddle helps me feel } \\
\text { more knowledgeable about Pharmacy Department activities and issues }\end{array}$ & $\begin{array}{c}\text { Strongly disagree } \\
\text { Somewhat disagree } \\
\text { Neutral } \\
\text { Somewhat agree } \\
\text { Strongly agree }\end{array}$ \\
\hline 5 & $\begin{array}{l}\text { The safety/operations huddle is currently scheduled at 7:05am in order to overlap } \\
\text { hand-off from overnight shift to day-shift. Please describe how the huddle affects } \\
\text { your work at this time }\end{array}$ & $\begin{array}{c}\text { Strongly disagree } \\
\text { Somewhat disagree } \\
\text { Neutral } \\
\text { Somewhat agree } \\
\text { Strongly agree }\end{array}$ \\
\hline 6 & $\begin{array}{c}\text { Ideally, what do you feel is the best time for the safety/operations huddle? Please } \\
\text { provide your answer in } 30 \text { minute increments }\end{array}$ & \\
\hline 7 & $\begin{array}{l}\text { Notes from the safety/operations huddle are posted on the pharmacy portal every day } \\
\text { and are kept for } 2 \text { weeks. Please described how often you have accessed these } \\
\text { documents }\end{array}$ & $\begin{array}{c}\text { Never } \\
\text { Rarely } \\
\text { Sometimes } \\
\text { Frequently } \\
\text { Regularly }\end{array}$ \\
\hline 8 & $\begin{array}{l}\text { The safety huddle is now scheduled on the weekends. When you work the weekend } \\
\text { how often do you call into the huddle }\end{array}$ & $\begin{array}{l}0-25 \% \text { of the time } \\
25-50 \% \text { of the time } \\
50-75 \% \text { of the time } \\
75-100 \% \text { of the time }\end{array}$ \\
\hline 9 & What would make the safety huddles on the weekend more meaningful to you & \\
\hline 10 & Would a safety/operations huddle that spans day and evening shift be helpful & $\begin{array}{c}\text { Strongly disagree } \\
\text { Somewhat disagree } \\
\text { Neutral } \\
\text { Somewhat agree } \\
\text { Strongly agree }\end{array}$ \\
\hline
\end{tabular}




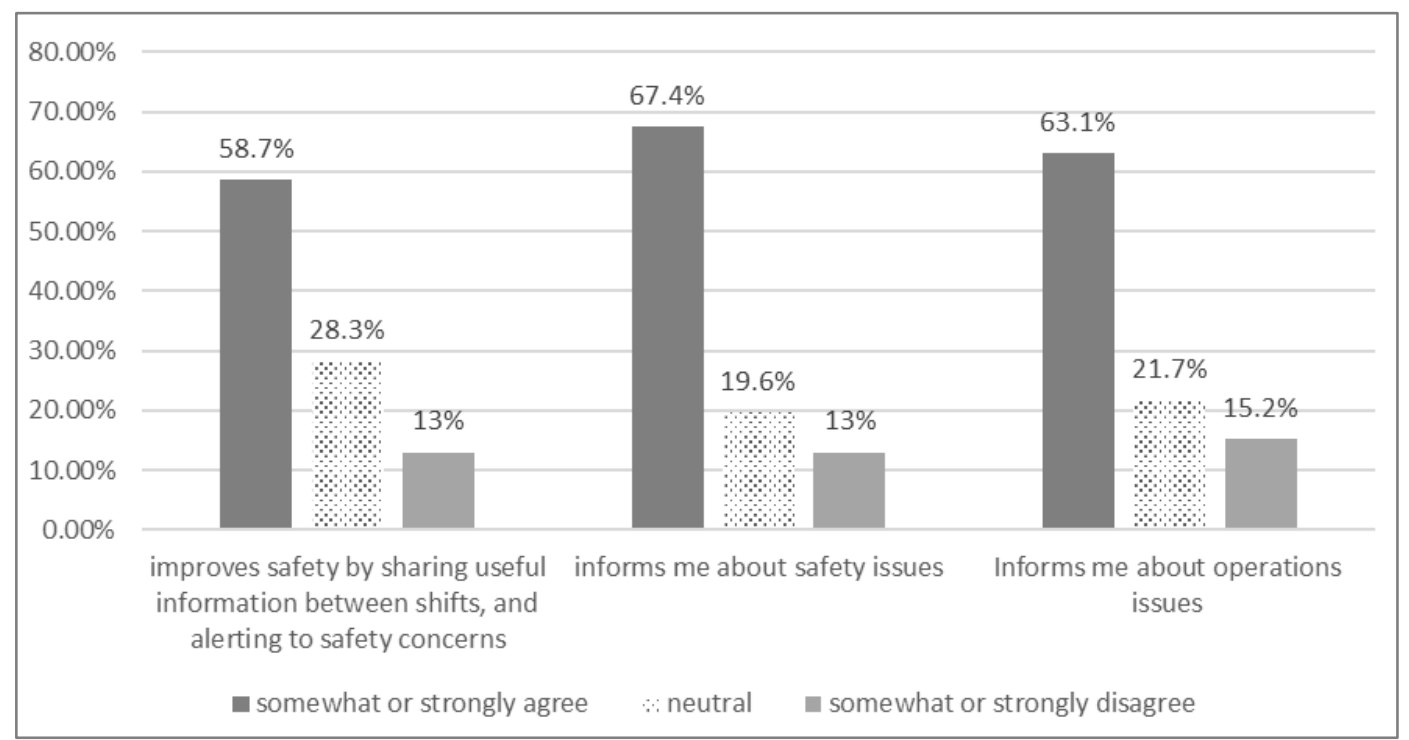

Figure 2. Huddle effectiveness staff survey responses

\section{Results}

The Redcap survey was used to determine the staff's perception of the benefit as well as a means to provide input to make improvements on the daily huddle. There were a total of 46 respondents out of a total of 195 pharmacy department employees for a $24 \%$ response rate. The survey questions/answers are described in Table 1. The questions targeted the 1) effectiveness of the huddle, 2) timing of the huddle, 3) distribution of information from the huddle, 4) weekend huddles, and 5) day/evening shift huddles. Responses are as follows.

\subsection{Effectiveness of the Safety/Operations Huddle}

Approximately $58 \%$ of staff answered that the safety/operations huddle was somewhat or very effective in sharing useful information between shifts whereas 13\% felt it was somewhat or very ineffective (Figure 2). When questioned whether the huddle informed them about safety issues $67 \%$ of respondents somewhat or strongly agreed whereas $13 \%$ somewhat or strongly disagreed. When asked whether the huddle informed them about operations issues $63 \%$ of those surveyed somewhat or strongly agreed and $15 \%$ somewhat or strongly disagreed. Lastly, $54 \%$ of the staff answered that they felt the safety/operations huddle made them more knowledgeable of pharmacy activities and issues, however approximately 1 in 5 somewhat or strongly disagreed that it made them more knowledgeable.

\subsubsection{Timing of the Safety/Operations Huddle}

A large majority of respondents (87\%) felt that the timing of the huddle did not interfere or somewhat interfered with their work with over half of respondents stating it did not interfere with their work. The best time identified by the staff for the huddle was $7 \mathrm{am}$ which was selected by $48 \%$ of respondents that answered that question. The remaining answers were distributed evenly over 9 different times.

\subsubsection{Distribution Model of the Daily Huddle Notes}

These notes were electronically stored daily on the pharmacy section of the hospital's portal and were maintained for 2 weeks. 58.7\% of the staff answered they rarely or never went to the website to look at the notes, and $19.6 \%$ answered that they frequently or regularly accessed these notes.

\subsubsection{Weekend Huddle}

Almost 2 in 3 respondents (65.2\%) indicated that, when working during the weekend, they would call into the weekend huddle $0-25 \%$ of the time, while $19.6 \%$ of the staff answered, they would call in more than $50 \%$ of the time. The staff identified consistently that huddles on the weekend did not have sufficient content presented and most recommending discontinuing the practice of weekend huddles.

\subsubsection{Day and Evening Shift Huddle}

When asked whether a huddle that spanned day and evening shift would be helpful, $30.4 \%$ of the staff somewhat or strongly agreed. The most common answer was neutral. 


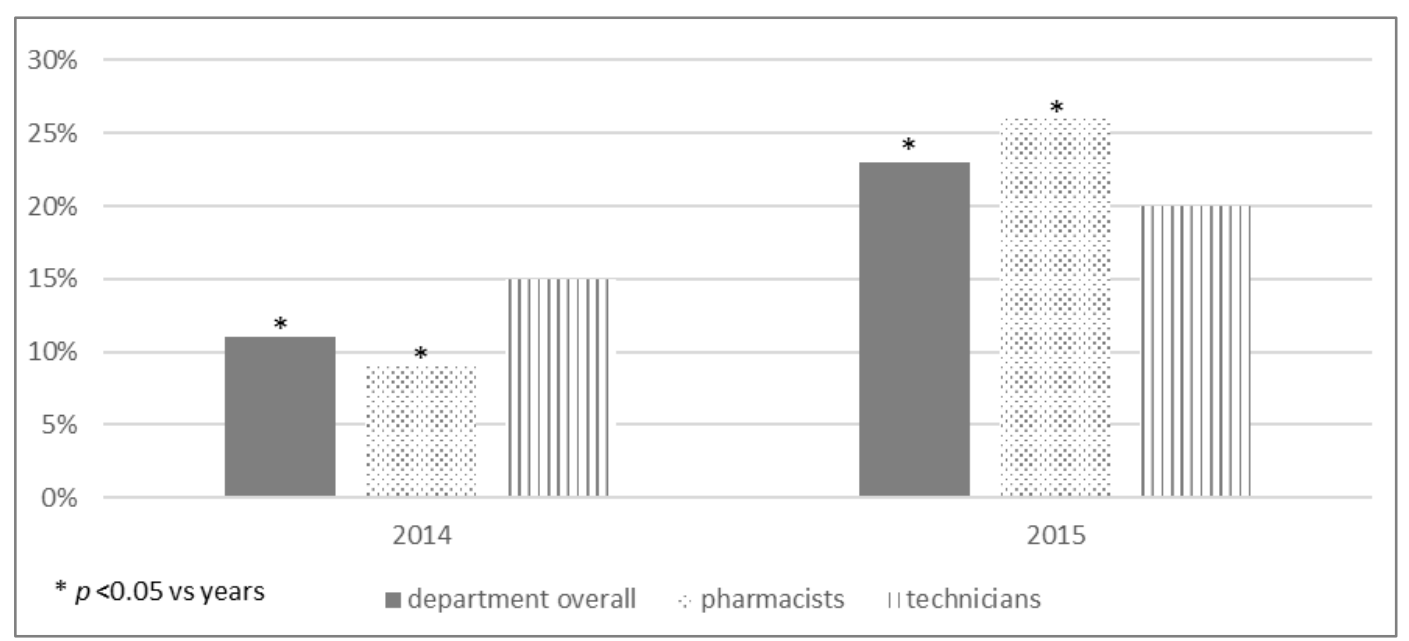

Figure 3. AHRQ patient safety culture survey: percentage of respondents giving overall safety grade of "excellent” before and after daily huddle implementation

\subsection{Agency for Healthcare Research and Quality (AHRQ) Data}

In 2014 the overall employee rated safety grade of “excellent” (vs. very good, acceptable, poor, failing) was given by, $11 \%$ of the pharmacy staff ( $9 \%$ by pharmacists and $15 \%$ by technicians). This survey was administered and results collected prior to the Daily Huddle. In 2015 approximately 8 months after the initiation of the huddle, this same safety grade was scored as excellent by $23 \%$ of the pharmacy staff (26\% by pharmacists and $20 \%$ by technicians). The $12 \%$ absolute improvement in excellent response from the pharmacy and the $17 \%$ absolute improvement in excellent response from the pharmacists was statistically significant $(\mathrm{p}<0.05)$ (Figure 3 ). The $5 \%$ absolute increase in excellent response for the technicians was not statistically significant. In 2016 the overall employee rated safety grade of excellent, was scored by $25 \%$ of pharmacy staff ( $24 \%$ by pharmacists and $26 \%$ by technicians). None of these ratings on the 2016 survey were statistically different from the 2015 scores.

\subsection{Hood Cleaning Documentation}

There are 7 pharmacy areas that have laminar flow hoods or biologic safety cabinets that require to be cleaned and that cleaning must be documented every shift that the area is open. Over a 4 week period prior to reporting on the huddle the completion rate was $95.4 \%$ (32 missed documentations). Over a 4-week period after "Roll call" implementation the completion rate was 99.9\% (1 missed documentation), an improvement that was statistically significant $(\mathrm{p}<0.05)$. The greatest improvements were seen in the South tower IV center $86.1 \%$ before versus $100 \%$ after and the 10th floor satellite in the North tower $92.6 \%$ before and $100 \%$ after "Roll call".

\section{Discussion}

Data have demonstrated that huddles are effective tools for providing real time information that is relevant for staff of a department. The goal was to determine the staff's perceptions of our huddle. Some of the most important questions were whether the staff believed that the huddle was effective in communicating safety and operation issues. Approximately 2/3 of the staff believed that it effectively accomplished both of those goals. Although less positive responses were answered whether staff felt more knowledgeable of pharmacy activities and issues, a majority still agreed the huddle was successful at making them more knowledgeable.

This significant impact on staff's perception of improvement of communication of safety issues with the huddle is corroborated by an improvement in a standardized survey (Agency for Healthcare Research and Quality [AHRQ] survey). AHRQ is an organization whose mission is to produce evidence to make health care safer, higher quality, more accessible, equitable, and affordable and to work within the U.S. Department of Health and Human Services. They provide a Hospital Survey on Patient Safety Culture, which is a staff survey that is designed to help hospitals assess the culture of safety in their institutions. The data is divided into 11 domains and can be analyzed at the user/department level, such as the pharmacy. Sivanandy [9] used a community tool developed from the Agency for Healthcare Research (AHRQ) Patient Safety Culture Survey to identify areas of strength and opportunity within their community, retail pharmacies in Malaysia. They reported the top box "excellent" score in the overall perception of safety in community pharmacy in Malaysia in $4.9 \%$ of participants. This is in contrast to an overall score of excellent by $25 \%$ of our respondents. Aboneh [10] also used this community tool to assess pharmacy personnel perceptions of the 
safety culture in community, retail pharmacies in the United States. UF Health Shands has administered this AHRQ survey annually since 2012. Not until 2014 did the pharmacy reach a significant participation rate (107 surveys completed). 2014 data has been used as the baseline data for this study. In 2015, the overall employee rated safety grade of excellent more than doubled and it is our belief that the daily huddle was a significant contributor to this success. In 2016 and 2017, the improvement in the overall employee rated safety grade of excellent has been sustained. Although there were no other major safety initiatives that were implemented between surveys, the improvements in the AHRQ score cannot definitively be attributed to the safety huddle. Nonetheless Herner [11] advocated for pharmacy departments to identify and assess interventions that can improve the safety culture. This daily safety huddle may be an intervention which has improved the standardized Patient Safety Score and the overall safety culture within our department.

Beyond assessing whether staff felt the huddle was effective, there was a desire to improve upon the huddle. Through questions, 5 and 6 of the survey the staff identified that 7:05 was an ideal time to hold the huddle. This is an overlap time between night shift and day shift. A standard question that is asked every day is whether or there are any mechanical or other issues that occurred for the night shift teams in each of the overnight locations. This allows night shift to pass off issues that have occurred over the past 8 to 10 hours. These issues are communicated and followed up immediately after the huddle. Issues that arise can include mechanical issues such as tube station delays or carousel failures, but also include operation issues such as par levels of compounded products. Based on the data it was recommended to continue the huddle daily at 7:05am.

With respect to the weekend huddles, the majority of staff (65.2\%) stated that they would call in to the huddle 0 to $25 \%$ of the time. Issues occur on the weekend as they do during the week, so it is somewhat surprising that a majority did not consistently call into the huddle. There are several likely causes for lower interest in participating on the weekend. As is common in many pharmacies, the number of staff that work during the weekend is less than during the week. Therefore, less people are available to both contribute and listen. One standard element of our huddle is that pharmacy related patient safety reports (PSR) are shared. Often these cases are shared once or twice per week. This information is provided by the medication safety pharmacist who works during the week. Pharmacy related PSRs were not reviewed over the weekend. During the week, either an assistant director or clinical staff pharmacist leads the huddles. These individuals are more aware of events that are occurring or are scheduled to occur within the 24-hour period. On the weekends, a PGY1 resident was leading the huddle, and had limited knowledge of issues and problems. Based on this feedback weekend huddles were discontinued. The same was true for the thought of having a day/evening shift huddle as less than $1 / 3$ of respondents responded positively about creating a day/evening shift huddle.

Huddles are intended to be quick meetings that describe issues or problems. The information should be limited to 24 hours before or after the huddle. The huddle is held live in one of our 2 main pharmacies and a teleconference line is active which allows multiple individuals to call in. The average number of callers into the huddle varies per month from 7 to 11 per call. There are staff that are unable to be present or call in (working evening shift, other responsibilities at the time of the call, etc) and therefore to be able to learn of the discussion from the huddle is important. Initially the notes would be typed up and saved on the Pharmacy portal of UF Health Shands website. Staff would then need to open the website, open the portal, drill down to the section where the huddles were stored, find the day's huddle notes and open. As demonstrated in question 7 , the majority of responses were that the never or rarely would check the Bridge. Continuing with that practice that was time intensive for the person that led the huddle, yet was rarely viewed by the staff, and did not make sense. Still an alternative means to provide this information daily for staff that could not participate live was necessary. Multiple suggestions as write in feedback from the survey were to provide the notes via email. Notes from the huddle are now emailed to the entire staff, typically within 15 to 30 minutes after the huddle. Timely distribution of these notes is important to provide this real time information. Important to note that the communication that is sent is merely discussion of the huddle. These notes are not intended to be documents that need to be stored, filed, and historically reviewed. Email is a great distribution tool, as once the pharmacy staff read the day's notes they can be deleted.

From an operational side the huddle has been used to communicate various processes. One such process that was included into the daily huddle was a reporting of the documentation of our hood cleaning. Every shift, every day when a technician cleaned the hood, the technician would document by initialing manually on a paper form. Although it was common that the technician would document the cleaning on the paper form, it was not always completed. Baseline data demonstrated that overall $95.4 \%$ of the time the technician documented the cleaning. Although this seems like a high percentage and measure of success, there were many cleanings that required documentation. $4.6 \%$ missed documentations equated to 32 missed documentations on our manual log. As these were not documented, actual cleaning could not subsequently be demonstrated. In each area that had a hood, the person working that morning was required to call into the huddle and report whether there were any missed documentations from the past 24 hours. After 4 weeks of reporting out daily on the huddle, the documentation rate increased to $99.9 \%$ or 1 failure in 702 
opportunities.

A template of the huddle notes is shown in Appendix 1. Some standard items that are reviewed daily include, drawing of an employee recognition card from all of last month's cards (monthly), patient safety reports (as needed), daily occupancy report, staffing issues, mechanical/overnight issues, and other issues. Other items are often rotated in such as Joint Commission talk points, clinical pearls, etc. Additional standing reports that are currently being considering include medication shortages as shortages have necessitated almost daily communication. Items that are discussed should be issues that are important to the individual pharmacy department's mission and issues that are critical to that department and hospital.

Huddles have become a standard practice, and there is a familiarity with the format as well as the utility. As staff have become accustomed to daily huddles, these huddles can be used for emergency situations. For example last fall several special huddles were held in preparation of Hurricane Irma. This allowed the communication of various topics such as hospital command center actions, departmental expectations (e.g. staffing needs), weather updates, and driving restrictions.

Culturally the impact of the daily huddle has empowered staff to communicate more often on potential safety issues. Anecdotally, the number of emails and number of staff (both pharmacists and technicians) that independently email the department or groups within the department has increased dramatically over the past 3 years. For example, if a technician finds an expired medication in a carousel or an automated dispensing cabinet, that person will email the department to make everyone immediately aware of that expired medication. The technician then asks the various areas to check their supply to ensure that they do not have the same expired product. Another example, is when patients with similar names are identified, an email as a name alert reminder is sent to double check before processing work on those 2 patients to prevent a wrong patient error. This practice of proactively communicating was not previously routinely performed. A department in which staff feel empowered to clearly communicate potential errors is a sign of a healthy culture where transparency and communication is valued. This type of culture is focused on preventing errors not assigning blame.

\section{Conclusions}

Daily safety huddles are advocated by many safety and regulatory type agencies as best practices. This daily safety/operations huddle allowed staff to feel more informed about safety and operational issues and to feel more knowledgeable about issues within the department. These perceptions have been validated in our AHRQ Hospital Survey on Patient Safety Culture. Improvements have been suggested by staff and those changes have been integrated in to the daily huddle. A survey was an effective tool to assess the daily safety/operations huddle and to better meet the needs of staff.

\section{Acknowledgements}

We are very grateful to Shawn Griffin for his help with this project as well as Carl Henriksen, Statistical Analyst, College of Pharmacy at the University of Florida for his assistance with statistics.

\section{Appendix 1. Template of Daily Huddle Notes}

UF Health Shands
Pharmacy Daily Safety/Operations Huddle
Date: 2-19-2018

\begin{tabular}{|c|l|l|}
\hline Reported Item & & Action taken \\
\hline TJC talking points & & \\
\hline Unfilled/unavailable beds & & \\
\hline Staffing issues & & \\
\hline Equipment issues & & \\
\hline Other & & \\
\hline
\end{tabular}

This communication and any attachments are privileged and/or confidential pursuant to the Patient Safety Act of 2005 and/or F.S. sections 395.0193, 395.0197, 766.101 or 766.1016. Do not disclose without approval of the Quality Department and/or Legal Services. DO NOT Copy or release. 


\section{REFERENCES}

[1] The Joint Commission, Quick Safety Advisory Issue 34; June 2017.

[2] Institute for Healthcare Improvement; ihi.org/tools, accessed February 2018.

[3] Agency for Healthcare research and Quality; Daily Huddle Component Kit, www.ahrq.gov, accessed March 8, 2018.

[4] Kylor C, Napier T, Rephann A, Spence S. Implementation of the Safety Huddle, Critical Care Nurse Vol.36, No.6, 80-82.

[5] Guo M, Tardif G, Bayley M. Medical safety huddles in rehabilitation: A novel patient safety strategy, Archives of Physical Medicine and Rehabilitation Oct 2017 advance online publication: www.archives-pmr.org.

[6] Menon S, Singh H, Giardina T, Rayburn W, Davis B, Russo E, Sittig D. Safety huddles to proactively identify and address electronic health record safety JAMIA Vol.24, No.2, 261-267.

[7] Traynor K, Pharmacists say safety huddles aid problem solving, American Journal of Health -System Pharmacy, Vol. 72, 767-768.

[8] Wilbur K, Scarborough K. Medication safety huddles: teaming up to improve patient safety, Canadian Journal of Hospital Pharmacy Vol.58, No.3, 151-155.

[9] Sivanandy P, Maharajan MK, Rajiah K, Wei TT, Loon TW, Yee LC. Evaluation of Patient Safety Culture among Malaysian Retail Pharmacists: Results of a Self-Reported Survey. Patient Preference and Adherence 2016:10; 1317-25.

[10] Adoneh EA, Look KA, Stone JA, Lester CA, Chui MA. Psychometric properties of the AHRQ Community Pharmacy Survey on Patient Safety Culture: a Factor Analysis. BMJ Qual Saf 2016; 25: 355-63.

[11] Herner SJ, Rawlings JE, Swartzendruber K, Delate T. Pharmacy Survey on Patient Safety Culture: Benchmarking Results. J Patient Saf 2017; 13: 37-42. 